\title{
Incidence of heterotopic gastric mucosa in the upper oesophagus
}

\author{
F Borhan-Manesh, J B Farnum
}

\begin{abstract}
In a prospective study of the frequency and clinical importance of heterotopic gastric mucosa in the upper oesophagus, 634 consecutive veteran patients ( $98 \%$ male), undergoing endoscopy for various gastrointestinal complaints, were evaluated. Sixty four patients $(10 \%)$ had heterotopic gastric mucosal patches varying in size from $0.2-0.3 \mathrm{~cm}$ to $3 \times 4-5 \mathrm{~cm}$ often immediately below the upper oesophageal sphincter. Biopsies of these patches showed fundic type gastric mucosa with chief and parietal cells. The $10 \%$ prevalence is more than twice the highest reported prevalence rate of endoscopically detected patches in the upper oesophagus. The characteristic location of these patches at the sphincter area, their uniformly fundic type gastric mucosa, and their poor correlation with clinical and endoscopic evidence of gastro-oesophageal reflux support the hypothesis that they are congenital in nature.
\end{abstract}

The reported prevalence of endoscopically diagnosed heterotopic gastric mucosa in the area of the upper oesophageal sphincter varies from $<0 \cdot 1 \%{ }^{1}$ to $3 \cdot 8 \%$. $^{2}$ The wide variation in the frequency at the upper oesophagus seems to be related to the thoroughness with which the area of the sphincter is inspected for this abnormality. The clinical importance of heterotopic gastric mucosal patches at the upper oesophageal sphincter area is debatable. In most large series these patches were found to be clinically unimportant. ${ }^{23}$ In other series upper oesophageal dysphagia has been attributed to these patches, though not always convincingly. ${ }^{1+6}$ Only $6 \%$ of 211 patients with patches studied retrospectively over 25 years 'complained' of cervical dysphagia. ${ }^{7}$ Nevertheless, there are still some less frequent and less controversial complications of these patches including ulcerative stricture at the upper oesophagus, ${ }^{8}$ oesophagotracheal fistula formation, ${ }^{9}$ upper oesophageal ring, ${ }^{10}$ and the development of adenocarcinoma. ${ }^{112}$

The pathogenesis of heterotopic gastric mucosa at the upper oesophagus is even more controversial. While some think that these patches are acquired and have the same pathogenesis as Barrett's mucosa in the distal oesophagus, ${ }^{13}$ others consider them to be congenital malformations. ${ }^{23614}$
The aims of the present study were threefold: (i) to determine more accurately the prevalence of the heterotopic gastric mucosal patches at the upper oesophagus; (ii) to clarify the pathogenesis of these patches (acquired $v$ congenital) in a large patient population; (iii) to evaluate the clinical importance of these patches.

\section{Patients and methods}

During a 13 month period (October 1987November 1988), 634 consecutive and unselected veteran patients ( $98 \%$ male), undergoing oesophagogastroduodenoscopy as part of gastrointestinal tract evaluation, were carefully examined by one of us (FB) for heterotopic gastric mucosal patches at the upper oesophagus. The age range was $19-85$ years, mean 61 years. Only three patients were black, consistent with the proportion of blacks in our patient population. Identified heterotopic gastric mucosal patches at the upper oesophageal sphincter area were photographed and biopsied. In patients with patches at the upper end and Barrett's mucosa at the lower end of the oesophagus, biopsy specimens were taken from the Barrett's mucosa as well. The sections were stained with haematoxylin and eosin and examined by the pathologist (JBF).

\section{Results}

\section{ENDOSCOPIC FINDINGS}

Sixty four of 634 patients $(10 \%)$ were found to have heterotopic gastric mucosal patches at the upper oesophagus. The patches were found just below the upper oesophageal sphincter with occasional proximal extension over the sphincter itself. They were usually on the lateral aspect of the inlet and measured from $0.2 \mathrm{~cm}-0.3 \mathrm{~cm}$ in diameter to $4-5 \times 3 \mathrm{~cm}$ in size. In 18 patients $(28 \%)$ the patches had diameters of less than $1 \mathrm{~cm}$. Except in two patients with very large patches which extended more transversely and covered almost two thirds of the luminal circumference, the longest diameter of the patches was longitudinal. They were velvety pale rose or salmon coloured, usually distinct from the surrounding pearl grey squamous oesophageal mucosa (Fig 1). Small patches were on raised surfaces and some patches had heaped up margins appearing as erosive ulcers. The patches were single in 29 patients ( $45 \cdot 3 \%$ ), multiple on opposite sides ('kissing patches') in 26 (40.6\%), 


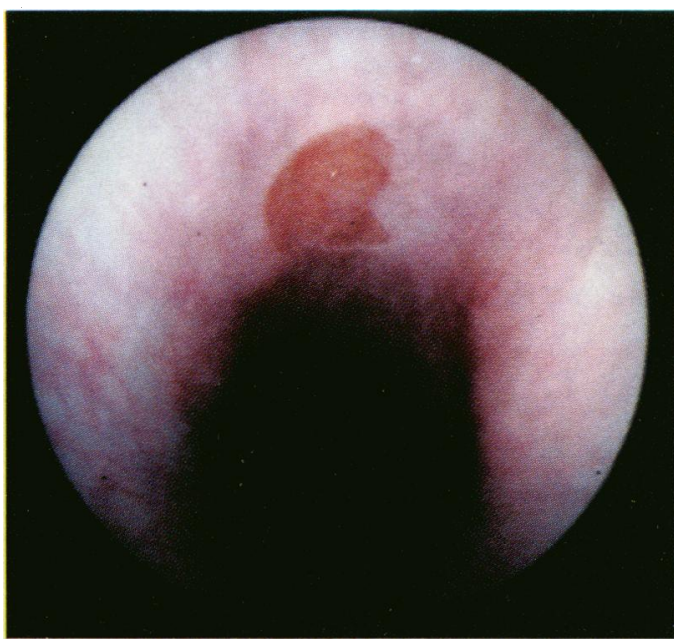

Figure 1: Endoscopic appearance of a single, salmon coloured patch of heterotopic gastric mucosa at the upper oesophageal sphincter area, surrounded by normal pearl grey squamous epithelium.

and multiple but one sided in nine patients (14\%) (Fig 2).

Twenty two of sixty four patients (34.3\%) had endoscopic evidence of gastro-oesophageal reflux disease, in the form of longitudinal, linear mucosal denudation and erosive ulcerations extending proximally from the lower oesophageal sphincter for various lengths. They were biopsied as indicated. Five of these 22 patients also had Barrett's mucosa; all were biopsied (Table).

\section{PATHOLOGICAL FINDINGS}

Sixty one of 63 patients who underwent biopsy of heterotopic gastric mucosa showed variable types of gastric mucosa. General adequacy of the biopsy was assessed by the presence of muscularis mucosa, which was absent in only four biopsy sets. Twenty eight patients showed a 'normal' or 'thin' body type mucosa with an orderly sequence of superficial glands containing surface columnar cells and mucous neck cells, and deeper glands showing uppermost parietal cells intermixed with more basaloid chief cells. This cellular order was consistent in all specimens containing mucous cells, chief cells, and parietal cells. The architecture of the 'normal' body type mucosa was identical to fundic biopsy specimens in the same patient and showed an approximate 1 to 4 ratio of superficial to deep glands (Fig 3). The 'thin' body type mucosa in heterotopic gastric mucosa was identical in cell composition to the 'normal' mucosa except for the extreme thinness and equal proportions of superficial and deep glands. Fifteen patients

Frequency of reflux oesophagitis and Barrett's mucosa in patients with and without heterotopic gastric mucosal patches at the upper oesophageal sphincter

\begin{tabular}{|c|c|c|c|}
\hline & $\begin{array}{l}\text { Patients } \\
\text { undergoing } \\
\text { oesophagogastro- } \\
\text { duodenoscopy }\end{array}$ & $\begin{array}{l}\text { No(\%) of } \\
\text { patients with } \\
\text { oesophagitis } \\
\text { (including } \\
\text { Barrett's) }\end{array}$ & $\begin{array}{l}\text { No(\%) of } \\
\text { patients with } \\
\text { Barrett's } \\
\text { mucosa }\end{array}$ \\
\hline $\begin{array}{l}\text { With patches } \\
\text { Without patches } \\
\text { Total }\end{array}$ & $\begin{array}{r}64 \\
570 \\
634\end{array}$ & $\begin{array}{r}22(34 \cdot 3) \\
218(38 \cdot 2) \\
240(37 \cdot 8)\end{array}$ & $\begin{array}{r}5(7 \cdot 8) \\
40(7 \cdot 0) \\
45(7 \cdot 0)\end{array}$ \\
\hline
\end{tabular}

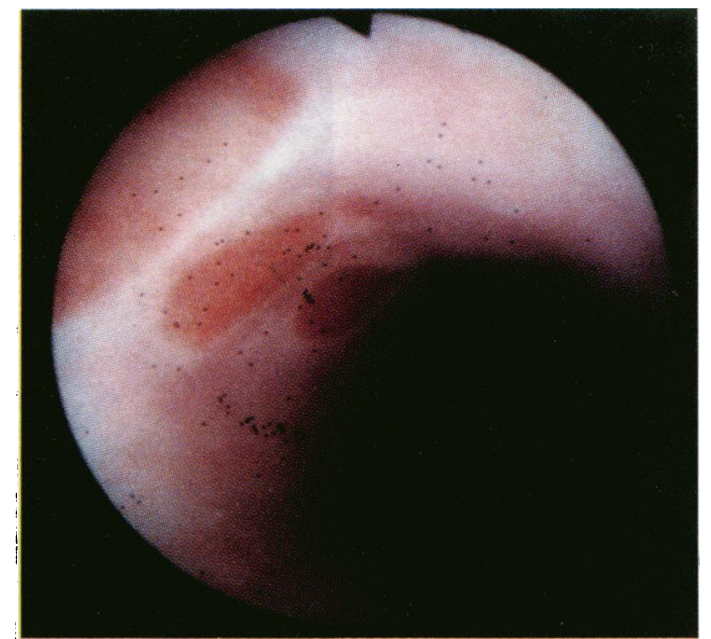

Figure 2: Multiple, one sided patches of heterotopic gastric mucosa, in a row, just below the upper oesophageal sphincter.

with heterotopic gastric mucosa showed a 'transitional' type of gastric mucosa with random admixture of fundic and antral glands. An 'antral' pattern in heterotopic gastric mucosa, defined as an absence of chief cells and less than $5 \%$ parietal cells, was found in 11 patients (Fig 4). Biopsy specimens from one patient were inadequate due to superficial sampling and fragmentation. One set of specimens in a patient with pernicious anaemia showed no parietal cells in heterotopic gastric mucosa or fundus despite multiple, adequate specimens. Distinctive, but uncommon, microscopic findings included hydropic cytoplasmic changes in parietal cells, occasional binucleate plasma cells, and rare nodular proliferation of plasma cells.

The architecture of the heterotopic gastric

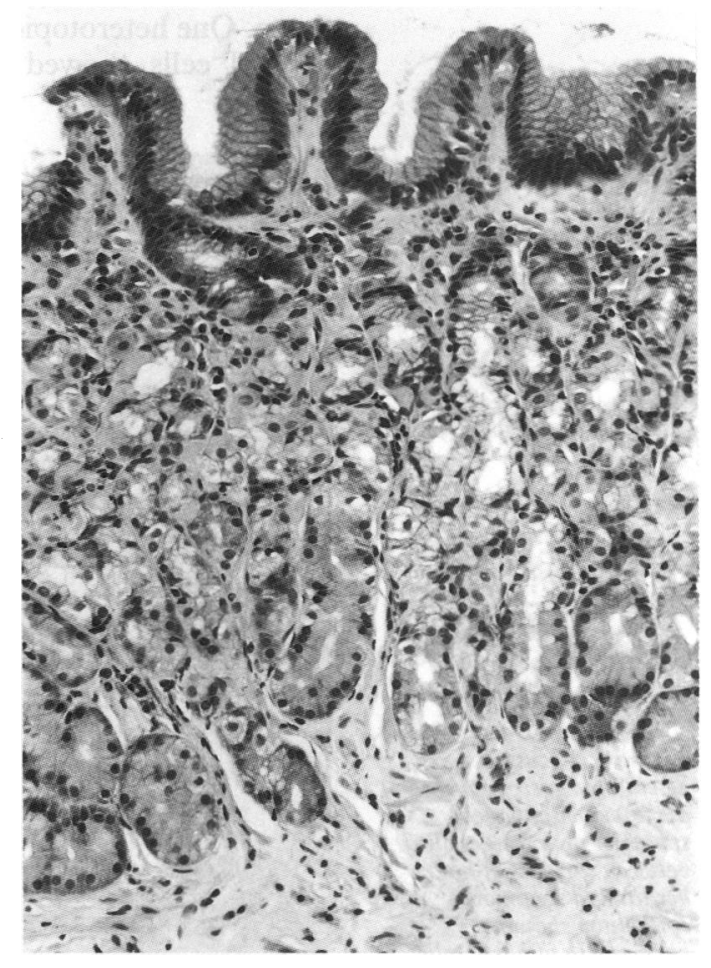

Figure 3: Heterotopic gastric mucosa at the upper oesophageal sphincter area showing body type gastric mucosa with well defined mucous neck cells and a deeper admixture of parietal and chief cells. (Haematoxylin $\mathcal{E}$ eosin; original magnification $\times 250$. 


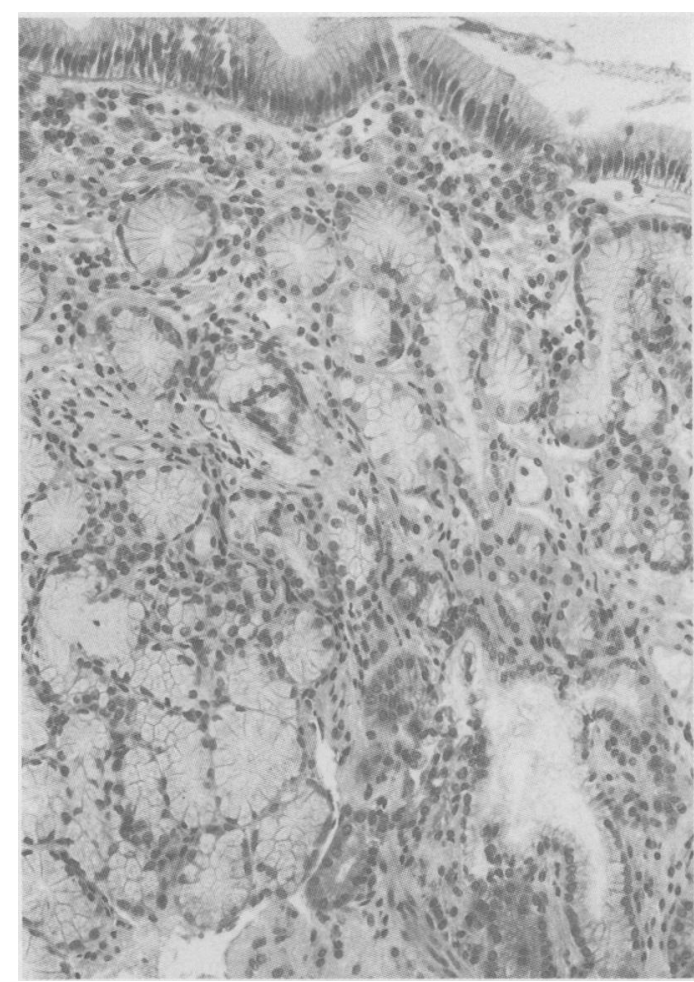

Figure 4: Heterotopic gastric mucosa at the upper oesophagea sphincter area showing antral type gastric mucosa with thin covering of mucous neck cells and deeper glands composed of mucous columnar cells and rare parietal cells. (Haematoxylin $\mathcal{E}$ eosin; original magnification $\times 250$.)

mucosa was distinctly divided into a normal or linear and lobular patterns. The linear pattern (21 patients) showed an intact fundic architecture with no intervening fibrous tissue. The lobular pattern (11 patients) showed distinct nodular aggregates of glandular mucosa, usually transitional or antral type, surrounded by fibrous tissue. One heterotopic gastric mucosa with rare parietal cells showed an arborising glandular

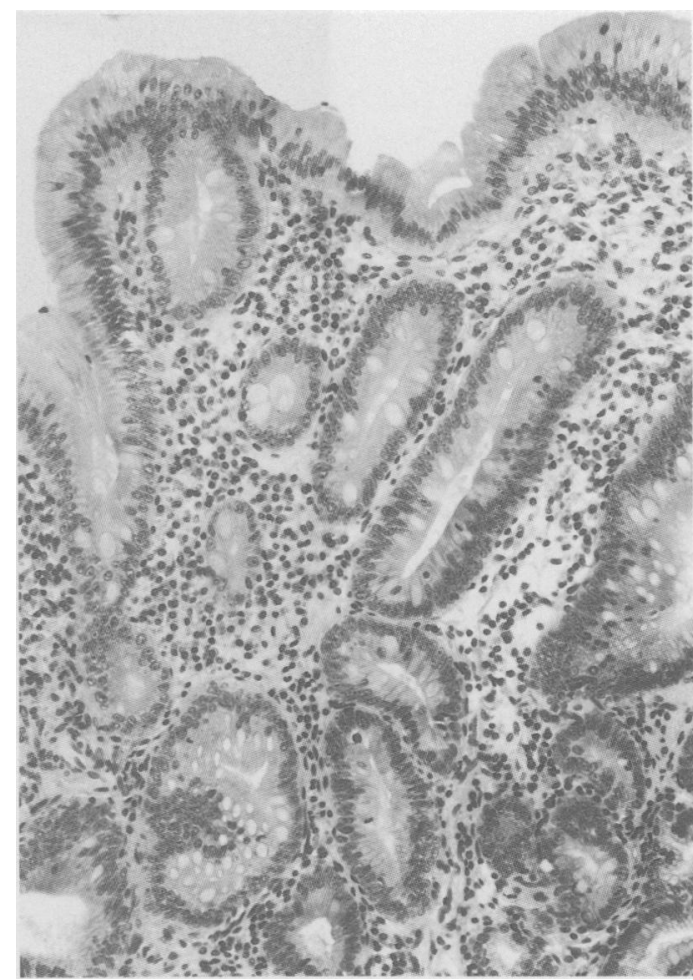

Figure 5: Barrett's epithelium at the lower oesophagus in a patient with concurrent heterotopic gastric mucosa patches at the upper oesophageal sphincter area, showing cardiac type columnar mucosa and intestinal metaplasia (no parietal cells present). (Haematoxylin $\mathcal{E}$ eosin; original magnification $\times 250$.)

pattern, mimicking oesophageal cardiac glands. Linear and lobular architectural patterns of heterotopic gastric mucosa were found in separate biopsy specimens from the same patch and juxtaposed on one specimen. Five biopsy sets were inadequate for assessment of architecture.

Inflammatory cell infiltrate was not prominent in biopsy specimens of heterotopic gastric
Figure 6: Focus of heterotopic gastric mucosa at the upper oesophageal sphincter area sandwiched between surfaces of nonkeratinised squamous epithelium showing hyperplasia of basal cells and elongation of papillas, features of chronic peptic oesophagitis. (Haematoxylin Es eosin; original magnification $\times 250$.)

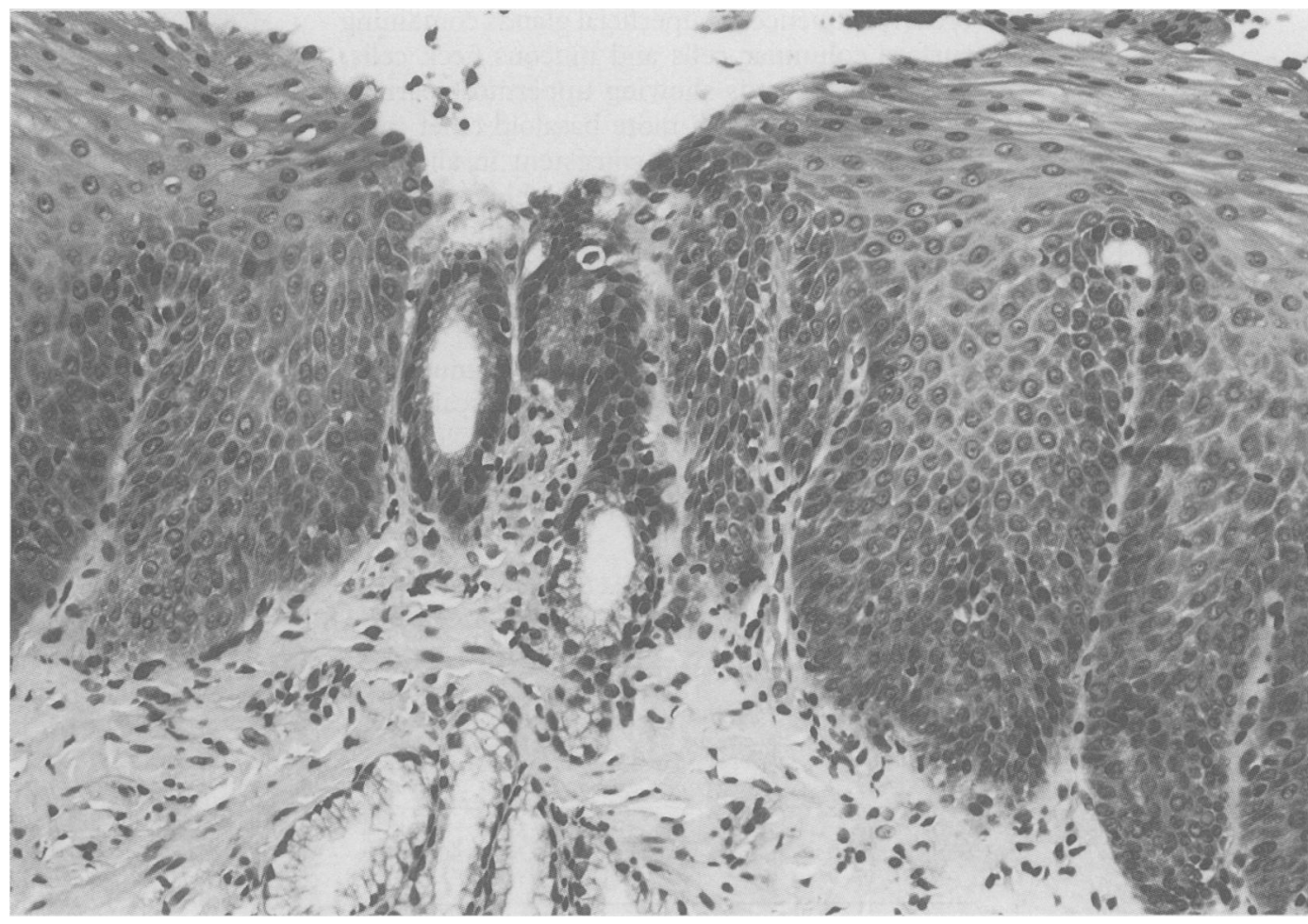


mucosa. Focal acute inflammation was detected in eight patients. Chronic inflammatory response was absent or mild in 31 patients, moderate in 31 , and severe in one. In the fundic type of heterotopic gastric mucosa no changes of chronic superficial gastritis or chronic atrophic gastritis were diagnosed.

Five patients with heterotopic gastric mucosa at the upper oesophageal sphincter area showed Barrett's epithelium with cardiac type columnar mucosa and variable intestinal metaplasia at the lower oesophagus (Fig 5); no parietal cells were present. Conversely, no intestinal metaplasia was found in heterotopic gastric mucosa of any type.

An impressive finding was coexistent chronic peptic oesophagitis in squamous mucosa adjacent to the heterotopic gastric mucosa. Chronic peptic oesophagitis was rated on the basis of basal cell hyperplasia and elongation of papillas. Of 55 patients with available squamous mucosa adjacent to heterotopic gastric mucosa for evaluation, there were seven patients with severe, 30 with moderate, and 18 with mild or suggestive changes of peptic oesophagitis. The most convincing biopsy specimens were those of juxtaposed squamous and columnar epithelium showing a severity of peptic oesophagitis inversely related to the distance from the mucosal patch (Fig 6).

The heterotopic gastric mucosa patch(es) discovered at the upper oesophagus could not explain the gastrointestinal symptoms in any of our patients.

\section{Discussion}

The prevalence of endoscopically identified heterotopic gastric mucosa patches at the upper oesophageal sphincter area has ranged from $<0 \cdot 1 \%$ to $3 \cdot 8 \%$ in previous studies, ${ }^{12}$ with the highest prevalence found in prospective studies specifically looking for these patches. ${ }^{26}$ The present data show that patches at this area are much more common. The upper end of the oesophagus harbouring these patches is the most neglected area in a routine oesophagogastroduodenoscopy, being either inadequately inspected or not inspected. There are several possible explanations for this. As the endoscope is introduced into the oesophagus during upper endoscopy, this area is already bypassed and unless there is a specific reason - that is, cervical dysphagia - the endoscope is often withdrawn without adequate inspection of this area. Repeated contractions of the upper oesophageal sphincter make thorough inspection, photography, and biopsy of this area very difficult.

The asymptomatic nature of these patches, simple oversight, and technical difficulty in inspecting the upper oesophageal sphincter area make many gastroenterologists and endoscopists unfamiliar with these lesions. Before embarking on the present study, professional staff at our centre were totally unfamiliar with the lesion. The high prevalence of heterotopic gastric mucosa patches at the upper oesophageal sphincter area in our series (one out of 10 patients) does not seem to reflect selectiveness of our patient population $(98 \%$ white male veterans) and probably reflects the true prevalence of these patches in at least the white male adult population in the United States. Our 10\% prevalence of endoscopically identified heterotopic gastric mucosa patches at the upper oesophageal sphincter area is consistent with the $10 \%$ incidence of patches, as readily identified by naked eye, in 300 necropsies on children aged $0-14$ years. $^{15}$

\section{PATHOGENESIS}

The following evidence supports the hypothesis that heterotopic gastric mucosa patches at the upper oesophagus are congenital in nature. Only 22 patients with patches had evidence of reflux oesophagitis $(34 \cdot 3 \%)$, including five patients with Barrett's mucosa at the lower third of the oesophagus. It is unlikely that the patches could have been acquired (as Barrett's) in nearly two thirds of our patients who failed to show any clinical or endoscopic evidence of gastrooesophageal reflux.

The constant and preferential location of these patches at the upper oesophageal sphincter area with no similar patches in other areas of the oesophagus supports their congenital origin. The upper oesophageal sphincter area should be the least accessible region for exposure to and damage by refluxed acid-pepsin in gastrooesophageal reflux disease. It is inconceivable that the entire oesophagus remains unscathed except for the sphincter area.

The frequency of oesophagitis and Barrett's mucosa in 64 patients with heterotopic gastric mucosa at the upper oesophageal sphincter was $34 \cdot 3 \%$ and $7 \cdot 8 \%$ respectively (Table). The frequency of similar lesions in 570 patients without heterotopic gastric mucosal patches was $38 \cdot 1 \%$ and $7 \%$, and not significantly different from those patients with patches at the upper oesophagus.

While the patches at the upper oesophageal sphincter area in five patients with simultaneous Barrett's lesions at the lower end of the oesophagus were pathologically of the fundic type with parietal cells, the Barrett's mucosa in the same patients was of metaplastic columnar epithelium without recognisable parietal cells.

Interestingly, patches were also occasionally found in the lower oesophageal area 1-3 cm above the gastro-oesophageal mucosal junction. Pathologically, these islets of heterotopic gastric mucosa show the same characteristics as the heterotopic gastric mucosa at the upper oesophageal sphincter.

Developmentally, at the $40 \mathrm{~mm}$ fetal stage, the oesophagus is lined by ciliated columnar epithelium and at about the $130 \mathrm{~mm}$ fetal stage the columnar epithelium in the mid-oesophagus is replaced by pseudostratified squamous epithelium spreading in cephalad and caudad directions. ${ }^{16}$ It seems that this replacement process is not always perfect and results in sequestered islets of gastric mucosa at either or both ends of the organ. It is possible that occasional cases of 'Barrett's' mucosa at the distal end of the oesophagus are nothing but the failure of the squamous epithelium to carpet the area resulting in 'Barrett's' epithelium. 
Hydrochloric acid secretion by heterotopic gastric mucosal patches has been shown by Hamilton et al and Jabbari et al in large patches of heterotopic gastric mucosal. ${ }^{12}$ In many of our cases the squamous epithelium distally adjacent to the patches showed changes consistent with reflux oesophagitis, probably as a result of continuous bathing of the mucosa by local acid production. There are a few reports attributing, though not always convincingly, symptoms such as cervical dysphagia to these patches. ${ }^{1+6}$ In view of the functional capacity of these patches to produce $\mathrm{HCl}$, it seems possible that the larger the patches are the more likely they are to produce symptoms. In fact most of the symptomatic cases reported had large patches.

Still much less frequent than cervical dysphagia are other complications of heterotopic gastric mucosal patches such as stricture formation, ${ }^{8}$ oesophagotracheal fistula, ${ }^{9}$ upper oesophageal ring, ${ }^{10}$ and adenocarcinoma. ${ }^{112}$ Interestingly, stricture and ring formations have been found only in patients with circumferential patches. ${ }^{810}$ In our series of patients, however, the patches were all asymptomatic at the time the patients were examined.

We are indebted to Dr John B Rodgers, Head, Division of Gastroenterology, Albany Medical College, for his comments, enterology, Albany Medical College,
suggestions, and review of this manuscript.
1 Hamilton JW, Thune RG, Morrissey JF. Symptomatic ectopic gastric epithelium of the cervical esophagus. Demonstration of acid production with Congo red. Dig Dis Sci 1986; 31: $337-42$.

2 Jabbari M, Goresky CA, Lough J, Yaffe C, Daly D, Cote C. The inlet patch: heterotopic gastric mucosa in the upper esophagus. Gastroenterology 1985; 89: 352-6.

3 VanAsche C, Rahm AE, Goldner F, Crumbaker D. Columnar mucosa in the proximal esophagus. Gastrointest Endosc 1988; 34: 324-6.

4 Miles Foxen EH. Ectopic gastric mucosa in the cervical esophagus, a possible cause of dysphagia. $\mathcal{F}$ Laryngol Otol 1957; 71: 419-23.

5 Raine $\mathrm{CH}$. Ectopic gastric mucosa in the upper esophagus as a cause of dysphagia. Ann Otol Rhinol Laryngol 1983; 92: 656.

6 Shah KK, DeRidder PH, Shah KK. Ectopic gastric mucosa in proximal esophagus. F Clin Gastroenterol 1986; 8: 509-13

7 Ollyo JB, Savary M, Monnier Ph, Fontollier Ch, Wellinger J, Levi F, et al. Is heterotopic columnar epithelium in the esophagus clinically relevant. Gastroenterology 1988; 94: A333.

8 Steadman C, Kerlin P, Teague C, Stephenson P. High esophageal stricture: a complication of 'inlet patch' mucosa. Gastroenterology 1988; 94: 521-4.

9 Kohler B, Kohler G, Riemann JF. Spontaneous esophagotracheal fistula resulting from ulcer in heterotopic gastric mucosa. Gastroenterology 1988; 95: 828-30.

10 Weaver GA. Upper esophageal web due to a ring formed by a squamoculamnar junction with ectopic gastric mucosa (another explanation of the Patterson-Kelly-Plummeranother explanation of the Patterson-Kelly-Pl
Vinson Syndrome. Dig Dis Sci 1979; 24: 959-63.

11 Carrie A. Adenocarcinoma of the upper end of the oesophagus arising from ectopic gastric epithelium. Br $\mathcal{F}$ Surg 1950; 37: 474

12 Danoff B, Cooper J, Klein M. Primary adenocarcinoma of the upper oesophagus. Clin Radiol 1978; 29: 519-22.

13 Rattner HM, McKinley MJ. Heterotopic gastric mucosa of the upper esophagus (letter). Gastroenterology 1986; 90: 1309.

14 Wang MMJ, Spear M, McGrew W. Heterotopic gastric mucosa of the esophagus. South Med $\dot{\mathcal{F}} 1986 ; 79$ : 633-5.

15 Variend S, Howat AJ. Upper oesophageal gastric heterotopia: a prospective necropsy study in children. $\mathcal{J}$ Clin Pathol 1988 ; 41: $742-5$.

16 Johns BAE. Developmental changes in the oesophageal epithelium in man. $\mathcal{f}$ Anat 1952; 86: 431-42. 